Journal of Business \& Management (COES\&RJ-JBM)

ISSN (E): 2306-7179 ISSN (P): 2306-8043

Publisher: Centre of Excellence for Scientific \& Research Journalism, LLC

Online Publication Date \& Issue: $1^{\text {st }}$ October 2015, Vol.3, No.4, October 2015

http://centreofexcellence.net/J/JBM/JBM Mainpage.htm

\title{
The discount framing in different pricing schemes: Combined versus partitioned pricing
}

\author{
Matthew Lee, ${ }^{a}$ Dr. Frankie Law ${ }^{b}$ \\ ${ }^{a}$ International Academy of Management, 8/F, Morrison Plaza, 9 Morrison Hill Road, \\ Wanchai, Hong Kong \\ ${ }^{\mathrm{b}}$ IEM, Fudan University, 220 Handan Road, Yangpu District, Shanghai, China
}

\begin{abstract}
:
Pricing is one of the most sophisticated and critical issues which managers have to face. It is obvious that managers have been undervaluing the behavioural and psychological perspective of pricing for many years. With a clear understanding of behavioural pricing, managers are able to make extra profit for their firms. In the current study, I was interested in investigating exactly how manipulation of discounts in the combined pricing scheme and partitioned pricing scheme affects the purchase decisions of consumers, such as consumers' purchase intentions, value perceptions and motivation to purchase. In the experiment of this paper, the four scenarios were based on different pricing schemes and price discount framing, namely Combined/Non-discounted condition, Combined/Discounted condition, Partitioned/Nondiscounted condition and Partitioned/Discounted condition. The ultimate goal of this study is to provide further insight for managers so as they can identify and understand consumers' reactions from psychological and behavioural perspectives under different pricing schemes, as well as how consumers frame price discount in order to ethically capture additional profit from their businesses.
\end{abstract}

\section{Keywords:}

discounting; combined pricing; partitioned pricing.

\section{Citation:}

Lee, Matthew; Law, Dr. Frankie; The discount framing in different pricing schemes: Combined versus partitioned pricing; (2015) Journal of Business \& Management (COES\&RJJBM) Vol.3, No.4, pp.439-458. 


\section{Introduction}

Pricing is one of the most sophisticated and critical issues which managers have to face. Many managers mistakenly assume that consumers always look for the lowest price, and as such managers simply interpret pricing as the calculation of the correct price for a product and service. Indeed, there does in fact exist a bargaining zone, or zone of possible agreements, for buyers and sellers in each transaction (Thompson, 2012). The zone of possible agreements is a range between the reservation points of negotiators, thus meaning that the final settlement of the negotiation will fall within that zone. In other words, consumers have a zone of acceptance regarding the appropriate price of a particular product or service. If the product or service falls within the price range, consumers will consider it, otherwise they will reject it if the product or service falls out of that range. Therefore, consumers do not always look for the lowest price as long as the price falls within their zone of acceptance.

It is obvious that managers have been undervaluing the behavioural and psychological perspective of pricing for many years. With a clear understanding of behavioural pricing, managers are able to make extra profit for their firms. A study by Inman, McAlister and Hoyer (1990) demonstrated that without an actual price reduction, firms are able to increase retail profits by simply announcing sales in their stores. From the study, it is clearly shown that consumers occasionally perceive gains psychologically because of different ways of price framing, but not as an actual saving in monetary terms. Up until the last two decades, behavioural pricing has aroused interest and attention from academia in different domains. For instance, studies in the marketing field have examined the reference price in behavioural pricing (Janiszewski \& Lichtenstein, 1999; Krishnamurthi, Mazumdar, \& Raj, 1992; Lattin \& Bucklin, 1989). In addition, other scholars have studied behavioural pricing from a framing perspective (e.g., Grewal, Marmorstein, \& Sharma, 1996; Naipaul \& Parsa, 2001; Schindler, 1992; Thaler, 1985). The latest research has further extended behavioural pricing to consumer behaviour, psychology and cultural studies (Hu, Parsa, \& Zhao, 2006; Simmons \& Schindler, 2003). According to Miyazaki (2003), psychology of pricing can be defined as a pricing research which examines prices related to the behavioural elements of consumers. To be more specific, it covers consumers' intentions, perceptions, processes and evaluations of price information.

Nowadays many firms have begun to launch different pricing schemes to attract consumers, with massive discounts in order to arouse consumers' interests. Some firms may package their components as a whole, and sell to consumers with a single and all-inclusive price. On the other hand, some firms break down the package into different components, and sell to consumers with different, smaller prices. Managers try to use this price tactic to affect consumer behaviour in order to maximise gains for their firms (Manning, 2003). For instance, some online bookstores charge consumers $£ 9.99$ for a book, in addition to $£ 2$ for the shipping and handling fee. All of these extra charges are relatively small, thus meaning that consumers do not pay much attention and do not have a strong resistance to the extra charges. In this paper, the above two pricing schemes are termed combined pricing and partitioned pricing respectively (Morwitz, Greenleaf, \& Johnson, 1998). In other words, combined pricing is an integration of payment, whilst partitioned pricing is a segregation of payment. Furthermore, apart from presenting prices in different ways, price discounts have significant positive effects on consumers' perceptions of value (e.g., Darke \& Dahl, 2003; Inman, Peter, \& Raghubir, 1997; Urbany, Bearden, \& Weibaker, 1988). It is very common to see firms providing discounts to consumers almost everywhere, in order to strengthen the faith and confidence of consumers that prices are the lowest in the market.

Research in marketing and psychology has been examining consumers' reaction to different pricing schemes such as partitioned pricing, as well as the effects of discounting on consumer 
behaviour. However, very few studies have directly examined how consumers react when discounting is being manipulated in different pricing schemes, such as partitioned pricing. It is essential for managers to understand how consumers behave, and to know whether they can further maximise their profits by designing an attractive pricing scheme to promote their products and services. Interestingly, when facing different pricing schemes, consumers frame the gain and loss in different ways. According to the mental accounting theory (Thaler, 1985), consumers prefer integrated losses to segregated losses, and segregated gains to integrated gains. However, a number of studies have shown that there is no conflict between mental accounting theory and segregation of payment (e.g., Morwitz et al., 1998; Novemsky \& Kahneman, 2005; Kim, 2006). But what if the scenario were to become more complicated by, for example, manipulating discounts in different pricing schemes? Indeed, these conditions have never been investigated before.

Based on the prospect theory (Kahneman \& Tversky, 1979) and mental accounting theory (Thaler, 1985), it seems that consumers prefer integrated losses to segregated losses. On the other hand, consumers prefer segregated gains to integrated gains. Whilst this is a generalised concept, empirical studies have shown that there is a discrepancy between mental accounting theory (Thaler, 1985) and partitioned pricing scheme (e.g., Drumwright, 1992; Wang, 1996; Johnson, Herrmann, \& Bauer, 1999). Indeed, Morwitz et al. (1998) pointed out that by segregating a larger price component and a smaller price component, known as base price and surcharge respectively, the partitioned prices result in lower recalled prices than the integrated prices do. They have suggested that consumers process the base price more thoroughly than the surcharge, due to the heuristics such as anchoring and adjustment (Tversky \& Kahneman, 1974). Consumers intuitively anchor on the base price, and adjust upward to incorporate the surcharge. In Estelami's (2003) study, he showed that consumers usually focus on a single and important component which is the base price, even though the prices consist of multiple dimensions, such as the base price, percentage discounts, trade-in values and monthly fees. Consumers usually read the base price before reading the surcharge, and thus the anchoring effect is easily being created even though the surcharge is presented right next to the base price. Consequently, consumers process and evaluate the information with cognitive biases mainly influenced by the anchoring effect.

Interestingly, and as discovered by different studies, consumers have positive perceptions to discounts due to the value associated with the offer (e.g., Darke \& Dahl, 2003; Inman et al., 1997; Urbany et al., 1988). According to the transaction utility theory (Thaler, 1985), discounts provide two utilities to consumers, namely acquisition utility and transaction utility. Firms are able to manipulate the framing of price, and focus on the savings to increase consumers' purchase intentions and value perceptions by providing discounts to consumers. Thus, consumers often perceive gains in the deal, due to the fact that the smaller amount of money being paid is framed. Based on the meta-analysis conducted by Compeau and Grewal (1998), consumers' evaluations of a deal are positively enhanced if discounts are being used in transaction utility theory's framing perspective. However, providing discounts has also been criticised as a poor pricing strategy, as consumers have negative perceptions regarding the quality of the discounted products (Raghubir \& Corfman, 1999; Scott \& Yalch, 1980; Tybout \& Scott, 1983). This may lead to a lower demand in the future (Dodson, Tybout, \& Sternthal, 1978; Doob, Carlsmith, Freedman, Landauer, \& Tom, 1969).

From a psychological perspective, motivation affects consumers' information processing and decision making (e.g., Garbarino \& Edell, 1997; Goodstein, 1993; Greenwald \& Leavitt, 1984; Mackenzie \& Spreng, 1992; Maclnnis \& Jaworski, 1989). When consumers are highly motivated towards an objective, they are more likely to be more cautious, and look for additional detailed information in order to evaluate it more carefully. However, when consumers are less motivated, they put little effort into processing information and making 
decisions. If they are not interested in a particular product, they will not devote much attention to finding out what it is. Morwitz et al. (1998) discovered that if consumers are highly favourable to a particular brand, then they process the surcharge more carefully. On the other hand, if consumers are less favourable, they process the surcharge more carelessly, and perceive lower prices whilst also exhibiting higher intentions to purchase in partitioned pricing. Recent studies have found that when consumers engage in motivated reasoning, which is a cognitive biased decision making which allows consumer to reach an outcome that they want, consumers tend to process information with cognitive biases. In this case, consumers may jump to a conclusion which they want to achieve (Agrawal \& Maheswaran, 2005; Carlson, Meloy \& Russo, 2006; Jain \& Maheswaran, 2000).

There are two hypotheses in this study. First and foremost, according to Morwitz et al. (1998), consumers recall a lower price and have a higher demand in partitioned pricing than when faced with combined pricing. Consumers frame the savings, due to the discounts provided, as a further gain in the deal. In many studies related to behavioural pricing, different scholars have stated that demand is higher in partitioned pricing than that in combined pricing. It arouses my interest to further examine consumer behaviour when faced with different pricing schemes. It also seems interesting to include price discounts in the study in order to investigate how these frame consumer preferences. Thus, the first hypothesis is that discounting will increase demand of both the combined and partitioned pricing schemes. Discounting will also facilitate the demand of the partitioned pricing scheme to a greater extent than that of the combined pricing scheme. Secondly, as consumers' motivation to process information becomes higher, information seeking will be obviously more extensive (Duncan \& Olshavsky, 1982; Punj \& Staelin, 1983). Most consumers tend to have a strong belief that favourable information can be found during the search process, and a positive outcome can be reached at the end. It is essential to establish whether this is a relationship between consumers' motivation and information seeking, and further investigate whether these behaviours affect consumers' purchase intentions. Thus, the second hypothesis is that consumers with higher motivation towards the product, and thus higher likelihood to seek information, will be more likely to purchase the product.

In the current study, I was interested in investigating exactly how manipulation of discounts in the combined pricing scheme and partitioned pricing scheme affects the purchase decisions of consumers. By conducting an experiment, I introduced the product Google Glass with an addon component online storage service, and asked participants several questions regarding their preferences. Following this, demographic questions were given to participants, in order to gather information relating to their background. The objective was to examine consumer behaviour through a specific investigation of consumers' purchase intentions, value perceptions and motivation to purchase in different pricing schemes, whilst discounting was being manipulated in four scenarios of the experiment. The four scenarios were based on different pricing schemes and price discount framing, namely Combined/Non-discounted condition, Combined/Discounted condition, Partitioned/Non-discounted condition and Partitioned/Discounted condition. Finally, the ultimate goal of this study was to provide further insights for managers so that they can identify and understand consumers' reactions from psychological and behavioural perspectives under different pricing schemes, and how consumers frame price discounts, in order to ethically capture additional profit from their businesses. 


\section{Method}

\section{Participants}

The experimental sample comprised 345 participants. Among the participants were 131 males and 214 females, ranging between 17 and 49 years of age (mean age $=34.19$ years, SD $=$ 7.21). Participants were recruited through an agency, and were asked to complete a 10-minute survey through their computers online. All participants were native English speakers and came from the United Kingdom and Northern Ireland. An additional 20 participants in the experiment could not be included in the final sample for analysis due to the following reasons: did not complete the question about value perceptions $(n=4)$, did not answer the question about motivation to purchase $(n=4)$, did not disclose his or her gender $(n=1)$, did not disclose his or her age $(n=1)$, were categorised as outliers due to statistically insignificant age range (aged 55 or above, $n=6$ ), did not indicate his or her income level $(n=4)$.

\section{Procedure and design}

Participants used their own computers to complete the survey online. The online survey in the experiment was designed and run on Qualtrics Research Suite (Qualtrics, Provo, UT, U.S.A.). Participants first read an introduction to completing the survey. Participants were expected to take around 10 minutes to finish the survey, and had to answer questions about decision making in different situations. After reading the instructions, all participants were randomly assigned to one of the fours conditions of a 2 (Pricing: Combined, Partitioned) $\times 2$ (Framing: Non-discounted, Discounted) experimental design (see Fig. 1). The four experimental conditions were as follows:

(1) Combined/Non-discounted. The price of the Google Glass and the price of the online storage service were presented as a package in a single, combined price. No discount was provided to participants. The total price of the Google Glass and the online storage service was $£ 200$ (Fig. 1a).

(2) Combined/Discounted. The price of the Google Glass and the price of the online storage service were presented as a package in a single, combined price. A discount was provided to participants. The total price of the Google Glass and the online storage service was $£ 200$, which was reduced from the original price $£ 230$ (Fig. 1b).

(3) Partitioned/Non-discounted. The price of the Google Glass and the price of the online storage service were presented separately. No discount was provided in this condition. The Google Glass cost $£ 170$, which was the base price. The online storage service cost $£ 30$, which was the add-on price (Fig. 1c).

(4) Partitioned/Discounted. The price of the Google Glass and the price of the online storage service were presented separately. A discount was provided in this condition. The price of the Google Glass was £170, which was reduced from the original base price of $£ 195$. The price of the online storage service was $£ 30$, which was reduced from the original add-on price of $£ 35$ (Fig. 1d).

Before setting the prices in the experiment, I conducted a survey on Facebook (see Appendix A). I wanted to establish an appropriate price level, which would be accepted by most of the consumers. In the Facebook survey, participants were asked how much they would be willing to pay if they were interested in the Google Glass. In total, $72 \%$ of the participants were willing to pay $£ 100-£ 200$. Based on the results of the survey and a marketing analysis, it was concluded that $£ 200$ was a suitable reference price for the Google Glass among most of the consumers. In light of this, it seemed clear that a price of $£ 200$ was suitable for use a total price in the experiment. 
In each of the four experimental conditions, participants read different advertisements with different pricing schemes. They were given a description of the Google Glass and the online storage service, followed by an advertisement of the Google Glass and the online storage service to read at the beginning (see Appendix B). The only difference between the advertisements in the four conditions was the way in which the price and discount were presented. After reading the advertisement, participants answered questions regarding their decision making in relation to potentially purchasing the Google Glass (see Appendix C). Participants were asked three decision-making questions about the advertisement which they had just seen. First of all, participants indicated their purchase intentions on a six-point scale ( 1 = "very unlikely", 2 = "unlikely", 3 = "somewhat unlikely", $4=$ "somewhat likely", $5=$ "likely" and $6=$ "very likely"). Following this, participants provided their value perceptions on a six-point scale ( 1 = "very bad value for money", $2=$ "bad value for money", 3 = "somewhat bad value for money", 4 = "somewhat good value for money", $5=$ "good value for money" and $6=$ "very good value for money"). Participants then indicated their motivation to purchase on a six-point scale $(1=$ "very unlikely", $2=$ "unlikely", 3 = "somewhat unlikely", 4 = "somewhat likely", 5 = "likely" and 6 = "very likely"). Next, participants answered six demographic questions. The questions were related to gender, age, education level, employment status, income level and country. Finally, participants were asked to provide their e-mail address in order to receive points for completing this online survey. After participants had answered all of the questions, the survey came to an end.

\section{Analysis}

After collecting the data through Qualtrics Research Suite, all statistical analyses were conducted on SPSS 21.0 (SPSS Inc., Chicago, IL, U.S.A.). I wanted to ascertain consumers' purchase intentions from the first question, which concerned likelihood to purchase. In terms of the second question, which addressed value for money, I wanted to gauge consumers' value perceptions. Finally, through the third question, which addressed likelihood to seek information I wished to gauge consumers' motivation to purchase. For the analyses of factorial ANOVA, the dependent variables were the likelihood to purchase, value for money and likelihood to seek information. With three dependent variables, I conducted three sets of factorial ANOVA (general linear model) with Pricing (Combined versus Partitioned) and Framing (Non-discounted versus Discounted) as the independent variables. The assumptions for the ANOVA were tested. The assumption of normality was proved by Q-Q plots through a visual investigation, whilst the assumption of homogeneity of variance was met by the plot of residuals against predicted values. After thorough verifications, it was confirmed that these assumptions of the ANOVA had not been violated.

After conducting the factorial ANOVAs, I ran a bivariate correlation test between the likelihood to seek information and the likelihood to purchase, with a Pearson's correlation coefficient found in the analysis. Following this, data about the demographic characteristics of participants were used to investigate whether particular demographic or socioeconomic characteristics, such as high or low income, would affect consumer behaviour. I recoded the income level of participants from four variables into two variables, which were categorised as low income level (less than $£ 40,000)$ and high income level ( $£ 40,000$ or above). I also recoded the education level of participants from five variables into two variables, namely low education level (below bachelor's level) and high education level (bachelor's level or above). I conducted a bivariate correlation test between income level and education level. Following this, I ran another set of bivariate correlation between the likelihood to seek information and income level, followed by the bivariate correlation between the likelihood to seek information and education level. 


\section{Results}

The first analysis of factorial ANOVA with Pricing and Framing revealed that there was no effect of Pricing $(F(1,341)=0.12, p=0.73)$, no effect of Framing $(F(1,341)=0.27, p=$ $0.61)$ and no effect of interaction between Pricing and Framing $(F(1,341)=0.01, p=0.91)$ on likelihood to purchase. The second analysis of factorial ANOVA with Pricing and Framing showed that there was no effect of Pricing $(F(1,341)=0.06, p=0.80)$, no effect of Framing $(F(1,341)=0.36, p=0.55)$ and no effect of interaction between Pricing and Framing $(F(1$, $341)=0.01, p=0.91)$ on value for money. The third analysis of factorial ANOVA with Pricing and Framing reported that there was no effect of Pricing $(F(1,341)=0.32, p=0.57)$, no effect of Framing $(F(1,341)=0.30, p=0.59)$ and no effect of interaction between Pricing and Framing $(F(1,341)=0.01, p=0.95)$ on likelihood to seek information. Surprisingly, the results rejected the first hypothesis, and were in direct contrast with findings from Morwitz et al. (1998). From the results, it was clear that manipulation of discounts and presenting the prices in different pricing schemes had no effect on the demand. Furthermore, discounting did not facilitate the demand in the partitioned pricing scheme to a greater extent than that of the combined pricing scheme.

In the analyses of the bivariate correlation, likelihood to seek information was significantly and positively correlated with likelihood to purchase $(r=0.75, p<0.01$; Fig. 2), The results supported the second hypothesis that consumers with high motivation will be more likely to look for additional information, and thus purchase the product.

Furthermore, the likelihood to seek information was significantly and positively related to the income level $(r=0.18, p<0.01)$. This result showed that consumers with higher income are more likely to look for additional information related to the product, and are more motivated than consumers with lower incomes. The income level was also significantly and positively related to education level $(r=0.25, p<0.01)$, which indicated that people with high educational background earn more. There was also a significant positive correlation between likelihood to seek information and education level $(r=0.12, p<0.05)$. The data indicated that consumers with higher educational level are more likely to look for more additional information about the product.

\section{Discussion}

The results from three sets of factorial ANOVA are in stark contrast with the findings of Morwitz et al. (1998) with regard to partitioned pricing. Interestingly, this phenomenon is exactly in line with the criticisms of discounting. By offering discounts to consumers, they associate poor quality with the discounted product (Raghubir \& Corfman, 1999; Scott \& Yalch, 1980; Tybout \& Scott, 1983). The negative effects of discounting can be explained by way of the self-perception theory (Scott \& Tybout, 1979). The study showed that consumers shifted their focus to incentives such as price discount, instead of focussing on the quality of the product. Therefore, consumers perceive lower perceptions in product quality when the products are discounted. According to Darke and Chung (2005), when discounts are being manipulated by lowering the selling price without quality assurance, consumers perceive a negative price-quality effect. Most importantly, the negative price-quality effect outweighs the positive discount framing. They also pointed out a very important aspect, namely that the negative price-quality effect reduces the acquisition utility and the transaction utility for discounting. Due to the negative quality inferences, consumers perceive that they are getting products with lower quality when the price is lower, instead of products with the same quality.

In addition, since Google Glass is a new technological product which has never been truly launched onto the market, consumers may strongly associate the poor product quality with the 
price discount. There is usually no price discount for newly launched products in the market. Indeed, for advanced technological products in particular, managers often use a market skimming pricing strategy, and set a high price for high-end products when they are first launched onto the market. According to Miller's (2013) news report, although Google has not announced the price of the Google Glass, early testers paid US\$1,500 (equivalent to £963) in order to try the product. There is a significant difference between the price that the early testers paid and the price that I set in the experiment. If participants had known about the price before completing the online survey in the experiment, their reference price may have been much higher than that of the experimental price. They may have felt that they were being tricked. Indeed, this could have in turn made them feel uncomfortable about the price being set in the experiment, thus meaning that they would possibly perceive the Google Glass in the experiment as having poorer quality. Consumers view the discounted price as the true price of the product, instead of the initial, non-discounted price. Darke and Chung (2005) claimed that consumers are unwilling to adjust the price expectation upwards once they have perceived that the quality of the discounted product is lower. This certainly explains why the first hypothesis is rejected, and discounting does not increase the demand of purchasing.

Furthermore, Bertini et al. (2009) suggested that surcharges of add-on decrease demand. Thus, the online storage service, as an add-on in the experiment, might result in a decrease of demand. According to Hamilton and Srivastava (2008), consumers are more price sensitive to components with lower benefit in partitioned pricing. Participants might evaluate the online storage service as a component with lower benefits, as it was not directly associated with the Google Glass like delivery charges of the Google Glass. There are many substitutes for the online storage service in the market, such as portable external hard disks, memory cards and CD-ROMs. Indeed, the benefit of the online storage service was not particularly high for participants, and thus they were very sensitive to the price of the add-on in the experiment. This also explains why discounting does not facilitate the demand in partitioned pricing when compared to combined pricing.

My study also examined the importance of consumers' motivation. As shown from the experimental results, there is a significant positive correlation between likelihood to seek information and likelihood to purchase. This finding supported my second hypothesis, which was accepted. The results are in agreement with those from different studies regarding consumers' motivation (e.g., Duncan \& Olshavsky, 1982; Punj \& Staelin, 1983). Highly motivated consumers are more likely to become involved with and engage in information searching. Indeed, the experiment revealed a positive correlation between education level and likelihood to seek information. Generally speaking, consumers with higher educational level have higher cognitive ability, and are thus more likely to search for additional information. According to Park and Young (1986), high involvement can be categorised into two types, namely cognitive involvement and affective involvement. Cognitive involvement means consumers are interested in thinking about and processing information related to an offer or decision. Affective involvement means consumers are interested in expending their emotion and feelings when considering an offer. It is obvious that consumers have been engaging in cognitive involvement, or even affective involvement, especially when it comes to consumers with higher cognitive ability.

When consumers are highly involved in the information search process, they probably perceive a positive value and have strong confidence in the information due to confirmation bias (Kahneman, 2011). As a result of confirmation bias, consumers tend to look for confirmatory information which they believe is correct, and match their beliefs and hypotheses. However, they fail to find disconfirmatory information which is in contradiction with their thoughts. Thus, consumers tend to purchase a product based on the research which they have done, and believe that they have made a correct decision. In addition, the result of 
the positive correlation between income level and likelihood to seek information shows that richer consumers who have higher purchasing power are more likely to purchase the product following extensive research about the product. This is obviously true since their high education background provides them with professional knowledge in understanding information which they have been looking for, and their high purchasing power allows them to buy products that they like. Therefore, consumers are more likely to purchase a product as they have a positive perception of information related to it.

I am aware that there remains a great deal of room for improvement in terms of my experimental procedure and design. First and foremost, the experiment should be conducted in a laboratory where computers are provided to participants. In the experiment, participants used their own computers to complete the survey. Due to varying computer screen sizes, the advertisement of the Google Glass and the online storage service was presented in different sizes on the computer screens. Indeed, this means that the visual salience effect (Kim, 2006) may have been present during the experiment, and that participants might have reacted differently due to the visual salience effect. For example, if the price of the online storage service was less visually salient, participants would underestimate the total price and have higher purchase intentions in the partitioned pricing condition. Since standardised computers were not provided in the experiment, I did not know how significant the visual salience effect was when participants were completing the online survey. Moreover, the numerical figures in the experiment were too easy to process, as all of them were integer. In most of the previous studies (e.g., DelVecchio et al., 2007; Estelami, 2003; Kim, 2006; Morwitz et al., 1998), numerical figures usually ended with .99 or even more complicated decimal places. Participants may have easily seen through my experiment, and thus the experimental results may not have been as expected. In the future, additional pricing research should be conducted to investigate the effect of discounting in a mixed pricing strategy. Some managers use partitioned pricing up to a certain payment point, then combine pricing when the total payment is greater than the predetermined price. Thus, the question here seems to be; what about manipulating price discount in such a mixed pricing strategy? It is worthwhile to investigate and study the way in which consumers behave in such an interesting and complicated scenario.

In this article, I have investigated consumers' purchase intentions, value perceptions and motivation to purchase through manipulating price discounts in two different pricing schemes, namely combined pricing and partitioned pricing. The experiment revealed that discounting is strongly associated with poor product quality, and thus consumers do not frame the price discount as a gain in the deal. The negative price-quality effect plays a significant role in the study, and the effect of negative price-quality is greater than that of price discount framing when it comes to consumer perceptions. Consumers do not value the price discount as a gain, so they do not want to make a purchase regardless of how the discount and pricing presentation are framed. It is essential for managers to understand how consumers value a product and the pricing scheme. Consumers' motivation is also another aspect to which managers must devote a great of attention. Motivation influences consumers' decision making in a biased and self-serving manner, especially when the decision maker can justify his or her decision with reasonable explanations (Kim, 2006). If managers can motivate consumers through attractive marketing strategies such as announcing the sales or printing eye-catching advertisements, consumers tend to look for additional information regarding the product. Indeed, this means that consumers are more likely to purchase the product, as they are affected by the confirmatory information which they have found during the information seeking process. Most importantly, information seeking is related to consumers' purchase intentions and behaviour. As said from the beginning of this paper, consumers do not always look for the cheapest price. Many managers use advanced pricing models to compute the exact selling price, in order to generate the maximum profit for their firms. Indeed, managers 
must simply be aware of the consumer psychology and behaviour. The key is to always provide a psychologically attractive price to consumers. The price does not have to be the lowest in the market, as long as consumers feel that it is the cheapest.

\section{References}

Agrawal, N., \& Maheswaran, D. (2005). Motivated reasoning in outcome-bias effects. Journal of Consumer Research, 31(4), 798-805.

Bertini, M., Ofek, E., \& Ariely, D. (2009). The impact of add-on features on consumer product evaluations. Journal of Consumer Research, 36(1), 17-28.

Carlson, K. A., Meloy, M. G., \& Russo, J. E. (2006). Leader-driven primacy: Using attribute order to affect consumer choice. Journal of Consumer Research, 32(4), 513-518.

Compeau, L. D., \& Grewal, D. (1998). Comparative price advertising: An integrative review. Journal of Public Policy \& Marketing, 17(2), 257-273.

Darke, P. R., \& Chung, C. M. Y. (2005). Effects of pricing and promotion on consumer perceptions: It depends on how you frame it. Journal of Retailing, 81(1), 35-47.

Darke, P. R., \& Dahl, D. W. (2003). Fairness and discounts: The subjective value of a bargain. Journal of Consumer Psychology, 13(3), 328-338.

DelVecchio, D., Krishnan, H. S., \& Smith, D. C. (2007). Cents or percent? The effects of promotion framing on price expectations and choice. Journal of Marketing, 71(3), 158-170.

Dodson, J. A., Tybout, A. M., \& Sternthal, B. (1978). Impact of deals and deal retraction on brand switching. Journal of Marketing Research, 15(1), 72-81.

Doob, A. N., Carlsmith, J. M., Freedman, J. L., Landauer, T. K., \& Tom, S. (1969). Effect of initial selling price on subsequent sales. Journal of Personality and Social Psychology, 11(4), 345-350.

Drumwright, M. E. (1992). A demonstration of anomalies in evaluations of bundling. Marketing Letters, 3(4), 311-321.

Duncan, C. P., \& Olshavsky, R. W. (1982). External search: The role of consumer beliefs. Journal of Marketing Research, 19(1), 32-43.

Estelami, H. (2003). The effect of price presentation tactics on consumer evaluation effort of multi-dimensional prices. Journal of Marketing Theory \& Practice, 11(2), 1-16.

Garbarino, E. C., \& Edell, J. A. (1997). Cognitive effort, affect, and choice. Journal of Consumer Research, 24(2), 147-158.

Goodstein, R. C. (1993). Category-based applications and extensions in advertising: Motivating more extensive ad processing. Journal of Consumer Research, 20(1), 87-99.

Greenwald, A. G., \& Leavitt, C. (1984). Audience involvement in advertising: Four levels. Journal of Consumer Research, 11(1), 581-592.

Grewal, D., Marmorstein, H., \& Sharma, A. (1996). Communicating price information through semantic cues: The moderating effects of situation and discount size. Journal of Consumer Research, 23(2), 148-155.

Hamilton, R. W., \& Srivastava, J. (2008). When $2+2$ is not the same as $1+3$ : Variations in price sensitivity across components of partitioned prices. Journal of Marketing Research, 45(4), 450-461.

Hu, H. H., Parsa, H. G., \& Zhao, J. L. (2006). The magic of price-ending choices in European restaurants: A comparative study. International Journal of Contemporary Hospitality Management, 18(2), 110-122.

Inman, J. J., McAlister, L., \& Hoyer, W. D. (1990). Promotion signal: Proxy for a price cut? Journal of Consumer Research, 17(1), 74-81.

Inman, J. J., Peter, A. C., \& Raghubir, P. (1997). Framing the deal: The role of restrictions in accentuating deal value. Journal of Consumer Research, 24(1), 68-79.

Jain, S. P., \& Maheswaran, D. (2000). Motivated reasoning: A depth-of-processing perspective. Journal of Consumer Research, 26(4), 358-371. 
Janiszewski, C., \& Lichtenstein, D. R. (1999). A range theory account of price perception. Journal of Consumer Research, 25(4), 353-368.

Kahneman, D. (2011). Thinking, fast and slow (1st ed.). New York: Farrar, Straus and Giroux.

Kahneman, D., \& Tversky, A. (1979). Prospect theory: An analysis of decision under risk. Econometrica, 47(2), 263-291.

Kim, H. M. (2006). The effect of salience on mental accounting: How integration versus segregation of payment influences purchase decisions. Journal of Behavioral Decision Making, 19(4), 381-391.

Krishnamurthi, L., Mazumdar, T., \& Raj, S. P. (1992). Asymmetric response to price in consumer brand choice and purchase quantity decisions. Journal of Consumer Research, 19(3), 387400.

Lattin, J. M., \& Bucklin, R. E. (1989). Reference effects of price and promotion on brand choice behavior. Journal of Marketing Research, 26(3), 299-310.

Maclnnis, D. J., \& Jaworski, B. J. (1989). Information processing from advertisements: Toward an integrative framework. Journal of Marketing, 53(4), 1-23.

Manning, J. (2003). The proliferation of surcharging. Journal of Revenue and Pricing Management, 2(3), 255-260.

Miller, C. C. (2013, August 27). Technology isn't enough: Google wants its Glass to be chic, International Herald Tribune, p. 14.

Miyazaki, A. D. (2003). Guest editorial: The psychology of pricing on the Internet. Psychology \& Marketing, 20(6), 471-476.

Morwitz, V. G., Greenleaf, E. A., \& Johnson, E. J. (1998). Divide and prosper: Consumers' reactions to partitioned prices. Journal of Marketing Research, 35(4), 453-463.

Novemsky, N., \& Kahneman, D. (2005). The boundaries of loss aversion. Journal of Marketing Research, 42(2), 119-128.

Thaler, R. H. (1985). Mental accounting and consumer choice. Marketing Science, 4(3), 199-214.

Thompson, L. L. (2012). The mind and heart of the negotiator (5th ed.). Boston: Pearson Education Inc.

Tversky, A., \& Kahneman, D. (1974). Judgment under uncertainty: Heuristics and biases. Science, 185(4157), 1124-1131.

Tybout, A. M., \& Scott, C. A. (1983). Availability of well-defined internal knowledge and the attitude formation process: Information aggregation versus self-perception. Journal of Personality and Social Psychology, 44(3), 474-491.

\section{Tahles and Figures}

Figure I: The four experimsental ennditions

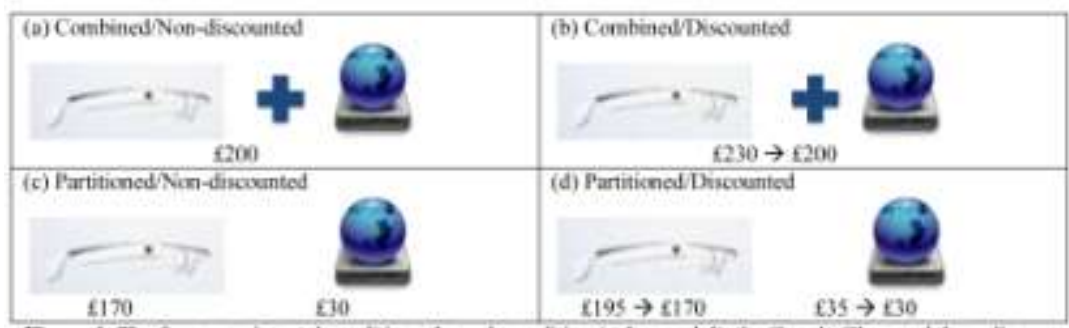

Figure 1 . The four experimental conditions. In cach condition $(\mathrm{a}, \mathrm{b}, \mathrm{c}$ and $\mathrm{d})$, the Google Gilass and the coline socages service were prescoted to participunts. In the Combined conditions (a and b), the price of the Google Glass and the price of the onlise storage serviee were presented as a package in a single, corsbined jrice, whereas in the Partitioned conditions $(\mathrm{c}$ and $\mathrm{d}$ ), the price of the Google Glass and the price of the crine stcenge service were presented neparatefy. In the Now-discousted condisions $\{a$ and $c\rangle$, no dincount was provided. uberess in the Discounted conditions ( $\mathrm{b}$ and $\mathrm{d}$ h a discount was provided. 
Figure 2: The bivariate correlation between likelihood to seek information and likelihood to purchase

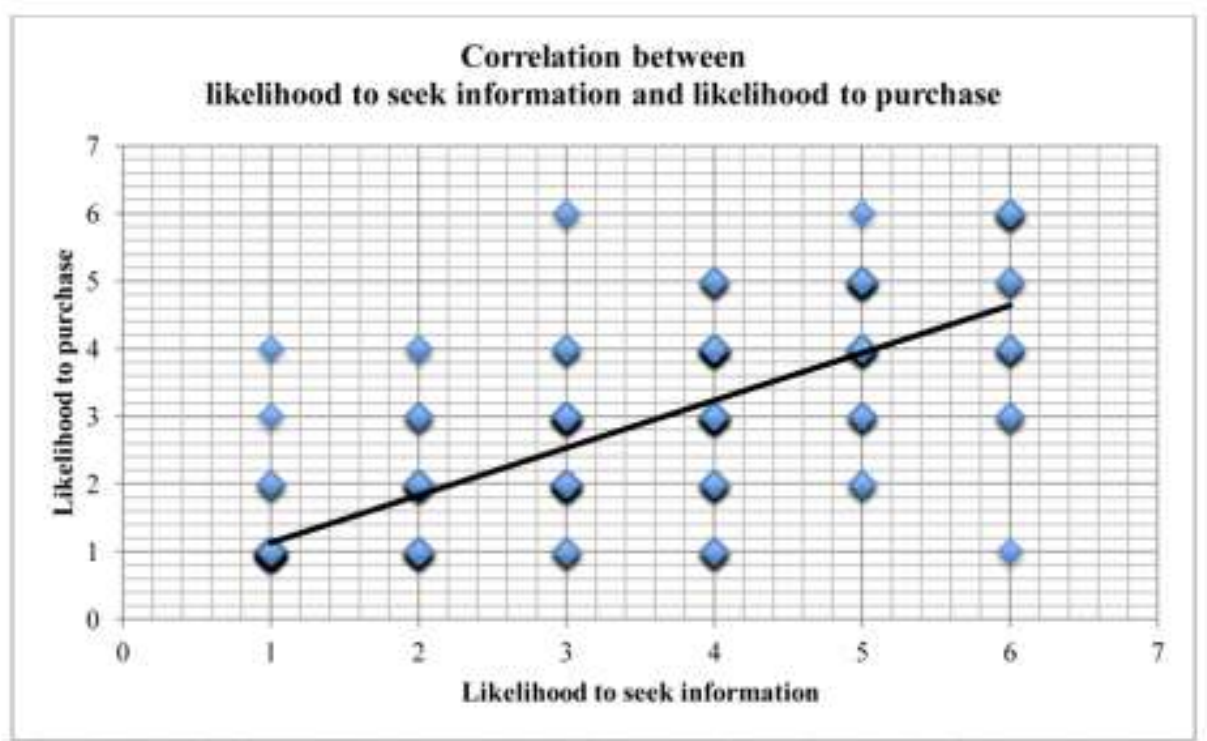

Figure 2. The bivariate correlation between likelihood to seek information and likelihood to purchase. A significant positive correlation was shown between likelihood to seek information and likelihood to purchase,

Appendices

Appendix A: Facebook survey

\section{Facebook survey}

\section{Imagine you are interested in the Google \\ glass product, how much would you \\ roughly be willing to pay for it?}

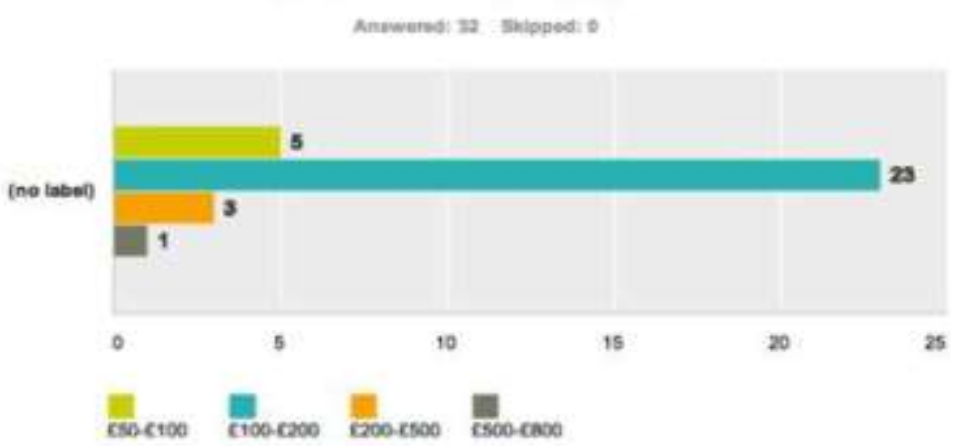

\begin{tabular}{|c|c|c|c|c|c|c|}
\hline & $c 50-5100$ & $6100-C 200$ & $2000-\operatorname{cscos}$ & $2500-6000$ & Tetent & $\begin{array}{l}\text { hrerson } \\
\text { husvo }\end{array}$ \\
\hline (no lateen) & $15.69 \%$ & nases & $9.30 \%$ & $213 \%$ & 22 & $2 x$ \\
\hline
\end{tabular}

Appendix B: Advertisements in the online survey

Combined/Non-discounted condition 
Journal of Business \& Management (COES\&RJ-JBM), 3(4), pp. 439-458

Google Glass

Rechargeable battery, 16GB flash total, 1GB RAM, $640 * 360$ pixels

\section{Online storage service}

Files are stored online, so you may access them everywhere!
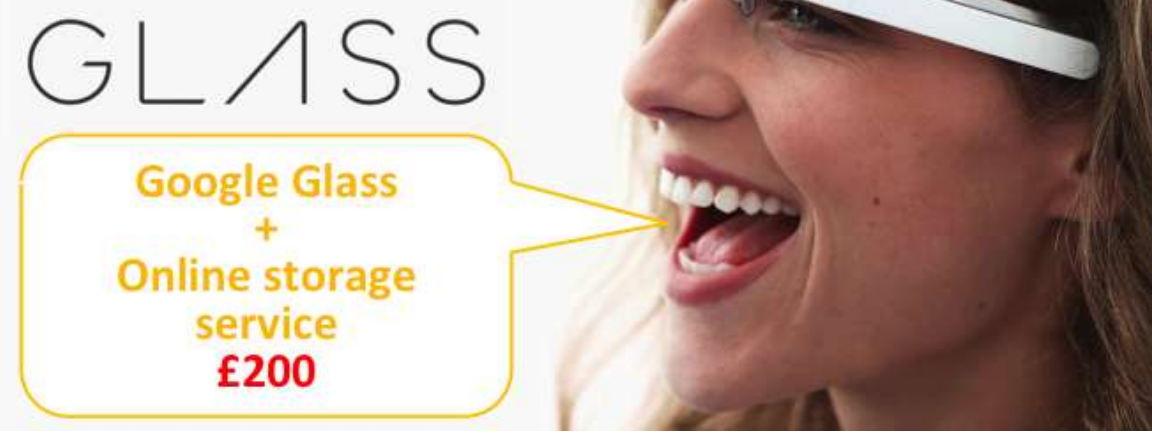

Combined/Discounted condition

\section{Google Glass}

Rechargeable battery, 16GB flash total, 1GB RAM, $640 * 360$ pixels

\section{Online storage service}

Files are stored online, so you may access them everywhere!

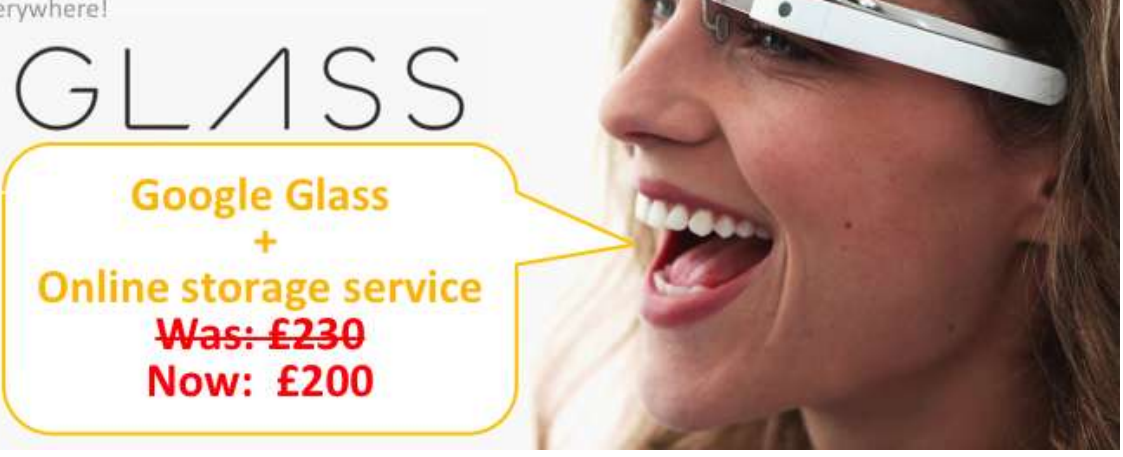


Partitioned/Non-discounted condition

Google Glass

Rechargeable battery, 16GB flash total, 1GB RAM, $640 * 360$ pixels

Online storage service

Files are stored online, so you may access them everywhere!

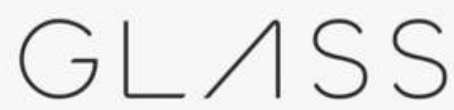

Google Glass: $\mathbf{1 1 7 0}$ $+$

\section{Online storage service: $\mathbf{f 3 0}$}

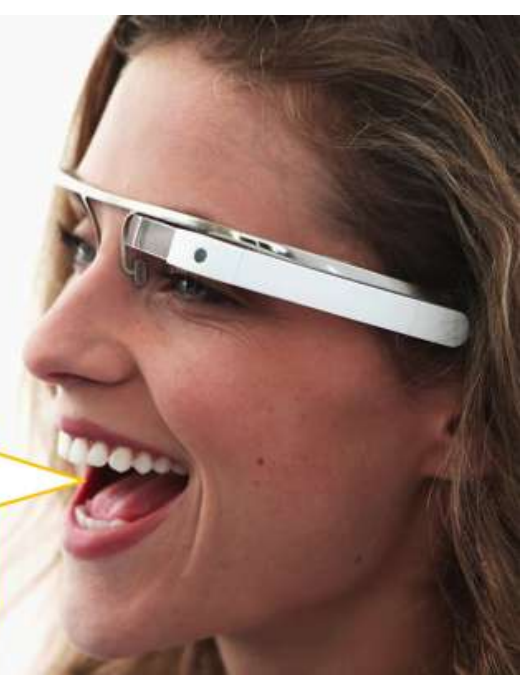

Partitioned/Discounted condition

\section{Goode Glass}

Aechargevble battery, 16G8 flash total, 1GB P.AM

$640^{*} 360$ poxels

\section{Online storage service}

Files are stored online, so you may accens them evermbere!

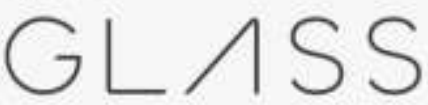

\section{Google Glass}

Was: $£ 195$

Now: $£ 170$

\section{Online storage service}

Was: $€ 35$

Now: $£ 30$

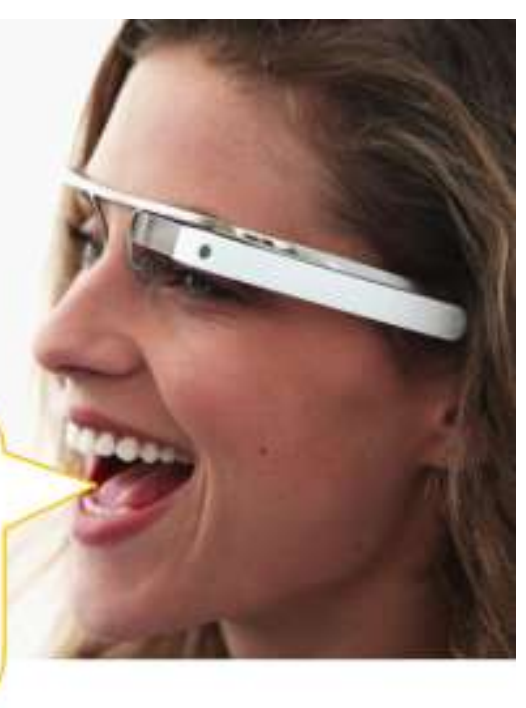


Appendix C: Online survey in the experiment

\section{Introduction}

This survey will take approximately 10 minutes to complete. It consists of several sets of related questions about decision making in different situations. The questions might require listening to some short music clips using headphones or speakers. All responses will remain anonymous. Please read the instructions and questions carefully. Thank you for participating! When you are ready to begin hit the arrow button.

\section{Combined/Non-discounted condition}

Google GL $\Lambda$ SS is a wearable computer with an optical head-mounted display (OHMD) developed by Google. It has the ability to take photos, Skype and record 720p HD videos. The side of Google GL $\Lambda$ SS is a touchpad, allowing users to control the device by swiping through a timeline-like interface displayed on the screen. The online storage service allows users to store their files online, so they may access the files everywhere.

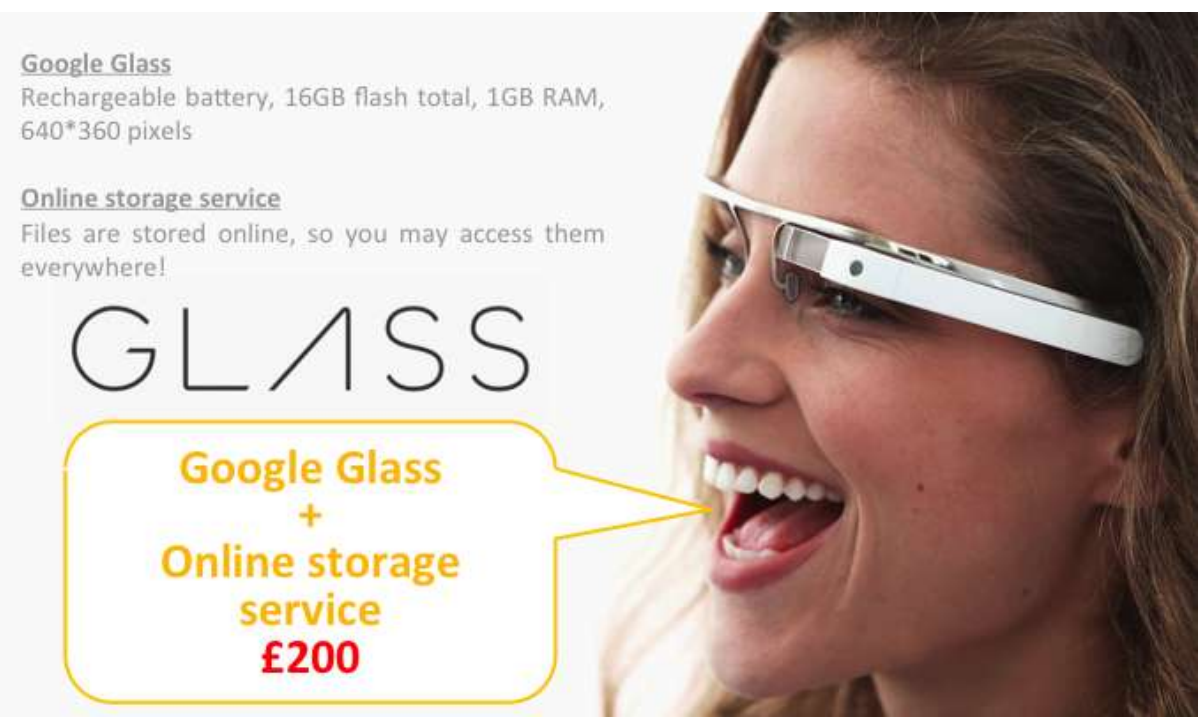

Q1 At this price, how likely are you to purchase the Google Glass offered in this ad? OVery Unlikely

OUnlikely

OSomewhat Unlikely

OSomewhat Likely

OLikely

OVery Likely 
Q2 The Google Glass offered in the ad is

OVery bad value for money

OBad value for money

OSomewhat bad value for money

OSomewhat good value for money

OGood value for money

OVery good value for money

Q3 How likely are you to search for further information about the Google Glass?

OVery Unlikely

OUnlikely

OSomewhat Unlikely

OSomewhat Likely

OLikely

OVery Likely

\section{Combined/Discounted condition}

Google GL $\Lambda$ SS is a wearable computer with an optical head-mounted display (OHMD) developed by Google. It has the ability to take photos, Skype and record 720p HD videos. The side of Google GL $\Lambda$ SS is a touchpad, allowing users to control the device by swiping through a timeline-like interface displayed on the screen. The online storage service allows users to store their files online, so they may access the files everywhere.

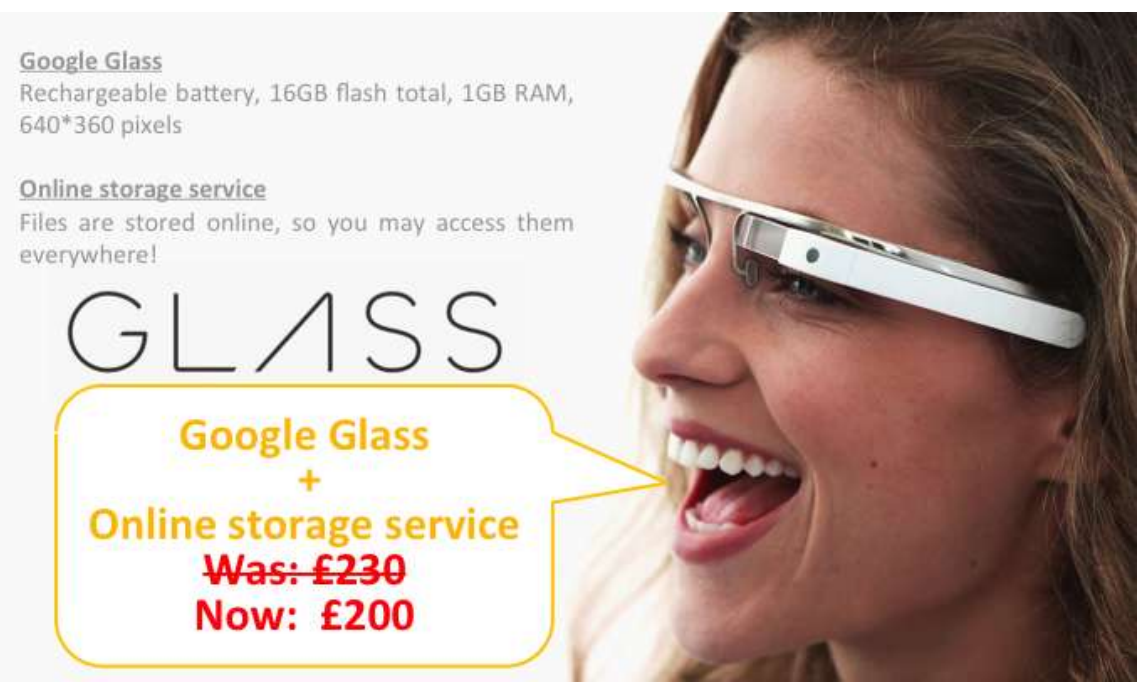

Q1 At this price, how likely are you to purchase the Google Glass offered in this ad? OVery Unlikely

OUnlikely

OSomewhat Unlikely

OSomewhat Likely

OLikely

OVery Likely 
Q2 The Google Glass offered in the ad is

OVery bad value for money

OBad value for money

OSomewhat bad value for money

OSomewhat good value for money

OGood value for money

OVery good value for money

Q3 How likely are you to search for further information about the Google Glass?

OVery Unlikely

OUnlikely

OSomewhat Unlikely

OSomewhat Likely

OLikely

OVery Likely

\section{Partitioned/Non-discounted condition}

Google GL $\Lambda$ SS is a wearable computer with an optical head-mounted display (OHMD) developed by Google. It has the ability to take photos, Skype and record 720p HD videos. The side of Google GL $\Lambda$ SS is a touchpad, allowing users to control the device by swiping through a timeline-like interface displayed on the screen. The online storage service allows users to store their files online, so they may access the files everywhere.

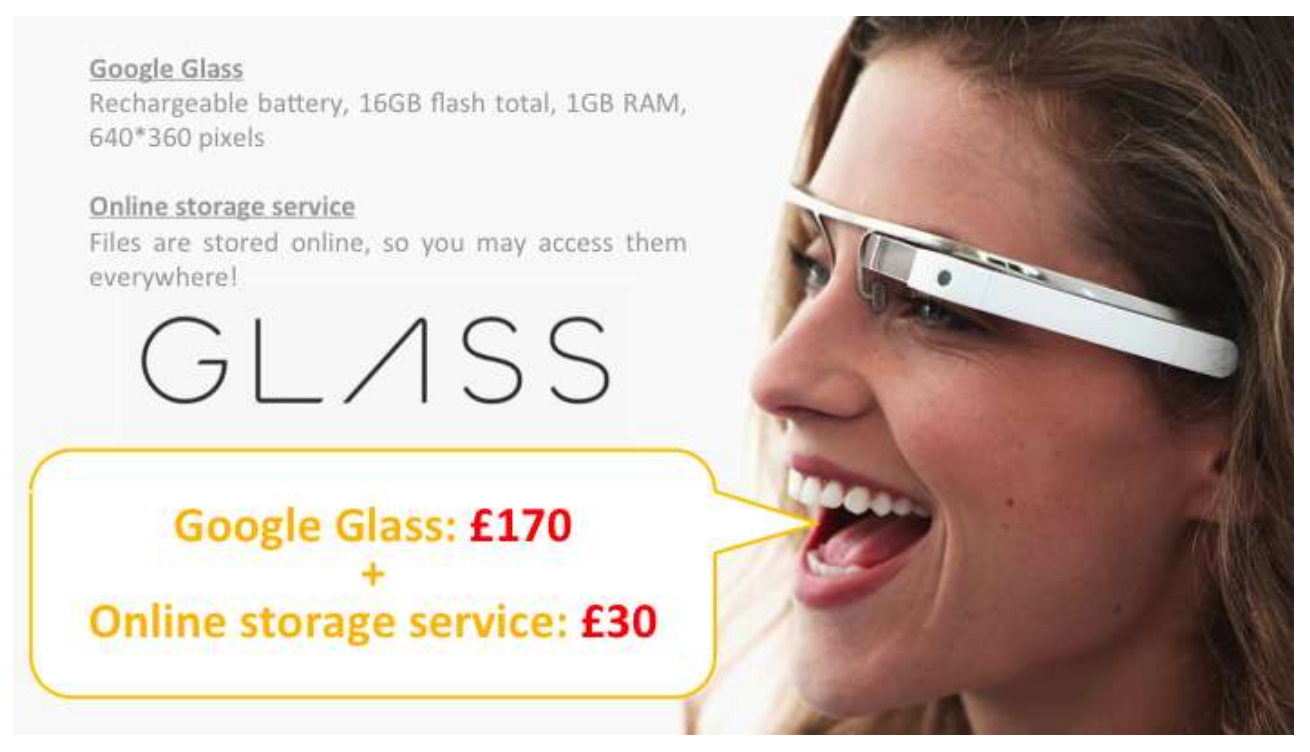

Q1 At this price, how likely are you to purchase the Google Glass offered in this ad? OVery Unlikely

OUnlikely

OSomewhat Unlikely

OSomewhat Likely

OLikely

OVery Likely 
Q2 The Google Glass offered in the ad is

OVery bad value for money

OBad value for money

OSomewhat bad value for money

OSomewhat good value for money

OGood value for money

OVery good value for money

Q3 How likely are you to search for further information about the Google Glass?

OVery Unlikely

OUnlikely

OSomewhat Unlikely

OSomewhat Likely

OLikely

OVery Likely

\section{Partitioned/Discounted condition}

Google GL $\Lambda$ SS is a wearable computer with an optical head-mounted display (OHMD)

developed by Google. It has the ability to take photos, Skype and record 720p HD videos. The side of Google GL $\Lambda$ SS is a touchpad, allowing users to control the device by swiping through a timeline-like interface displayed on the screen. The online storage service allows users to store their files online, so they may access the files everywhere.

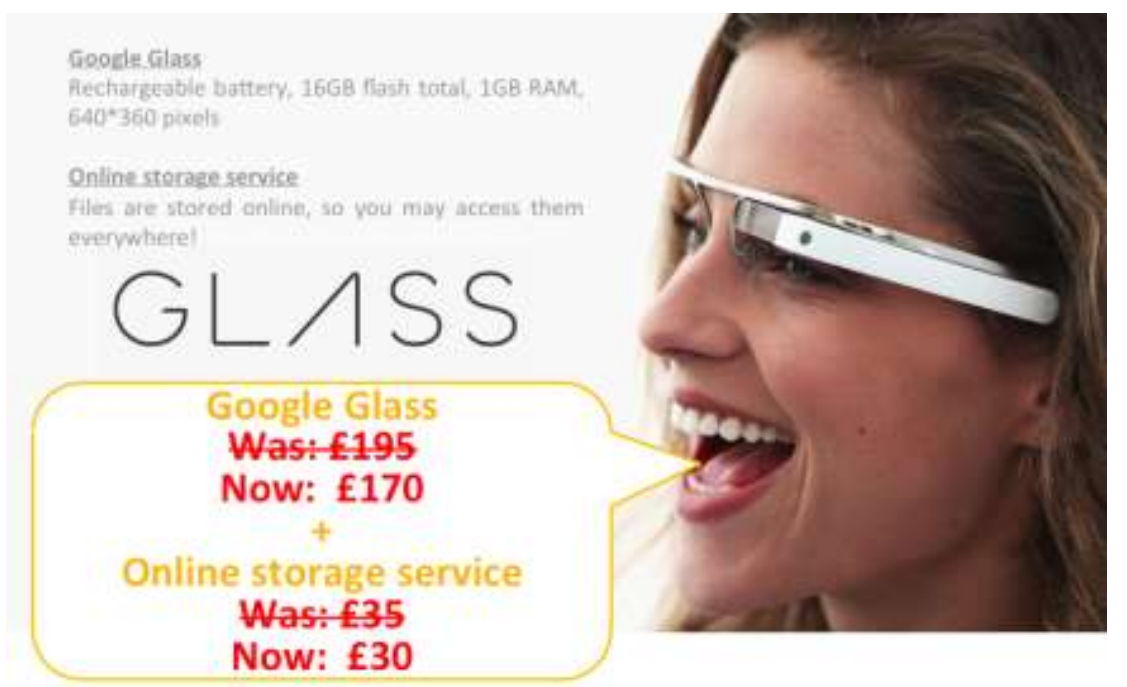

Q1 At this price, how likely are you to purchase the Google Glass offered in this ad? OVery Unlikely

OUnlikely

OSomewhat Unlikely

OSomewhat Likely

OLikely

OVery Likely 
Q2 The Google Glass offered in the ad is

OVery bad value for money

OBad value for money

OSomewhat bad value for money

OSomewhat good value for money

OGood value for money

OVery good value for money

Q3 How likely are you to search for further information about the Google Glass?

OVery Unlikely

OUnlikely

OSomewhat Unlikely

OSomewhat Likely

OLikely

OVery Likely

\section{Demographic questions}

You will next be asked to provide some basic information about yourself, and to answer a few additional questions.

Q4 What is your gender?

OMale

OFemale

Q5 What was your age at your last birthday?

Q6 What is the highest education degree you have earned?

\section{OGCSE}

OA levels

OBachelor's degree or equivalent

OMaster's degree or equivalent

$\mathrm{OPhD}$

OOther (specify)

Q7 What is your current employment status?

OEmployed

OUnemployed

OStudent

ORetired

OOther (specify)

Q8 Please provide a rough estimate of the total combined income of all members of your household in the last year.

OLess than $£ 20,000$

O£20,000 - £39,999

O£40,000 - £59,999

O£60,000 or more

OPrefer not to answer 
Q9 In which country do you currently reside?

\title{
End of survey
}

Q10 To receive your points please enter your Maximiles e-mail address below:

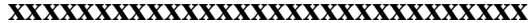

